\title{
Preparation and characterization of nano-CaO based on eggshell waste: Novel and green catalytic approach to highly efficient synthesis of pyrano[4,3-b]pyrans
}

\author{
Elaheh Mosaddegh*, Asadollah Hassankhani \\ Department of New Materials, Institute of Science and High Technology and Environmental Sciences, Graduate University of Advanced Technology, PO \\ Box 76315-117, Kerman, Iran
}

A R T I C L E I N F O

Article history:

Received 11 October 2013

Accepted 22 November 2013

Published 20 March 2014

\section{Keywords:}

Nano-calcium oxide

Biocatalyst

Pyrano[4,3-b]pyrans

Ball-mill
Eggshell waste

\begin{abstract}
A B S T R A C T
Nano-CaO was prepared by calcination of ball-milled chicken eggshell waste. This novel, bioactive, heterogeneous catalyst, which had high catalytic activity and reusability, was used in the green synthesis of pyrano[4,3-b]pyrans via condensation of various aromatic aldehydes, malononitrile, and 4-hydroxy-6-methyl-2H-pyran-2-one at $120{ }^{\circ} \mathrm{C}$ under solvent-free conditions. The reaction proceeded to completion within 5-45 $\mathrm{min}$ in $93 \%-98 \%$ yield. The nano-CaO was fully characterized by scanning electron microscopy, X-ray powder diffraction, infrared spectroscopy, X-ray fluorescence spectroscopy, and thermal gravimetric, surface area, and elemental analyses.
\end{abstract}

(C) 2014, Dalian Institute of Chemical Physics, Chinese Academy of Sciences. Published by Elsevier B.V. All rights reserved.

\section{Introduction}

Recently, there has been increasing interest in the development of clean technology to replace the use of hazardous reagents and catalysts with relatively environmentally benign compounds. Additionally, "green chemistry" emphasizes the optimization of synthetic methodologies to reduce pollution, costs, and tedious work-ups [1-3]. This new challenge has led to a growing interest in the use of natural and bio compounds for organic and inorganic application. Eggs, an abundant natural food source, are consumed worldwide because they contain essential amino acids, vitamins, and minerals. Chicken eggshell is totally biodegradable, recyclable, and biocompatible, with good osteoconductivity [4]. It consists of more than $90 \% \mathrm{CaCO}_{3}$ and has emerged as a novel bone substitute in its natural form [5-8]. This natural solid waste is non-hazardous, and is commonly disposed of in landfills without any pretreatment be- cause it has no traditional uses [9]. The eggshell structure is mesoporous, with the ability to form a nanoporous structure [10]. Substrates with nanostructures, dense nanopores, and high surface areas have found many application in biosensors, proteomics, light-emitting diodes [4,11-14], and tissue engineering [15-17]. We previously reported the first ultrasonic-assisted preparation of nano- $\mathrm{CaCO}_{3}$ based on eggshell waste, and its use as a heterogeneous catalyst in the green synthesis of 2-aminochromenes [16]. Eggshells have previously been used to synthesize nanoparticle apatite, hydroxyapatite nanopowders, and nano- $\mathrm{CaCl}_{2}$, but these require sintering or the use of acidic and hazardous solvents to make porous scaffolds [18-20]. In this paper, we report a green, simple, and cheap approach to making nano- $\mathrm{CaO}$ based on chicken eggshell waste. We also characterized the nano-CaO structure and investigated its use as a catalyst in the green synthesis of pyrano[4,3-b]pyrans.

\footnotetext{
* Corresponding author. Tel: +98-342-6226611; Fax: +98-342-6226617; E-mail: emosaddegh@gmail.com 


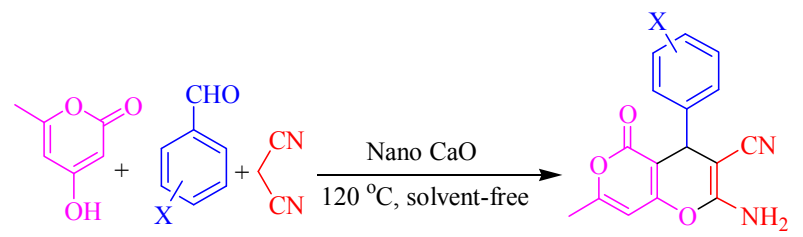

Scheme 1. Synthesis of 2-amino-7-methyl-5-oxo-4-phenyl-4,5-dihydropyrano[4,3-b]pyran-3-carbonitrile derivatives.

It is known that many pyran derivatives exhibit a wide spectrum of pharmacological and biological activity [21-23]. Moreover, they have been shown to have important medicinal properties such as antimicrobial [24], antiviral [25,26], antiproliferative [27], antitumor [28], anticancer [29], anti-HIV, antituberculosis, anti-inflammatory, and antifungal activity [30-35]. Despite their wide range of pharmacological and industrial application, the synthesis of pyrano[4,3- $b]$ pyrans has received little attention. Recently, members of this important class of pyran derivatives have been synthesized via one-pot multicomponent condensation reactions of aryl aldehydes, malononitrile, and 4-hydroxy-6-methyl-2H-pyran-2-one in the presence of different reagents. Various reagents such as $\mathrm{KF}-\mathrm{Al}_{2} \mathrm{O}_{3}$ [36], [bmim] $\mathrm{BF}_{4}$ [28], piperidine [37], and $\mathrm{NH}_{4} \mathrm{OAc}$ [38] have been used to accomplish this transformation. However, in spite of their potential utility, all of these methods suffer from one or more disadvantages, such as unsatisfactory yields, very prolonged reaction time, and the use of organic solvents. So, in a continuation of our efforts to develop new green chemistry methods $[39,40]$, we decided to explore the green synthesis of 2-amino-7-methyl-5-oxo-4-phenyl-4,5-dihydropyrano[4,3-b]pyran-3-carbonitrile derivatives in the presence of nano-CaO based on eggshell waste as a novel and green biocatalyst, under solvent-free and thermal conditions (Scheme 1).

\section{Experimental}

\subsection{Materials and Instruments}

All chemicals were of analytical grade, purchased from Merck, and used as received. Melting points were determined using a Gallenkamp melting-point apparatus and are uncorrected. Nuclear magnetic resonance (NMR) spectra were recorded at $500\left({ }^{1} \mathrm{H}\right)$ and $125.77\left({ }^{13} \mathrm{C}\right) \mathrm{MHz}$ using a Bruker DRX-500 Avance spectrometer. Fourier-transform infrared (FT-IR) spectra were obtained using a MATSON 1000 FT-IR spectrophotometer. X-ray diffraction (XRD) was performed using a D8 Bruker diffractometer ( $40 \mathrm{kV}$ and $40 \mathrm{~mA}$ ) with $\mathrm{Cu} K_{\alpha}$ radiation $(\lambda=0.154 \mathrm{~nm})$ to analyze the crystal structure of the milled powders. The XRD patterns were recorded in the $2 \theta$ range $20^{\circ}-80^{\circ}$ with a step size of $0.01^{\circ}$. The mean size and size distribution of the eggshell powder were measured using a dynamic laser light scattering apparatus (FRITSCH Analysette 22 NanoTec Laser Particle Sizer). The chemical composition of the catalyst was determined using X-ray fluorescence (XRF) spectroscopy (Microanalyser Unisantis XMF-104, Germany) operated at $40 \mathrm{kV}$ and $300 \mathrm{~mA}$, with Mo radiation. Thermo- gravimetric analysis-differential thermal analysis (TGA-DTA) experiments were carried out using an STA 409 PC Luxx thermal analysis instrument (NETZSCH, Germany) under a flow of nitrogen. The sample mass used was about $20 \mathrm{mg}$, and the temperature ranged from 25 to $900{ }^{\circ} \mathrm{C}$, with a rising rate of 10 ${ }^{\circ} \mathrm{C} / \mathrm{min}$. The film cross-section morphology was examined using field-emission scanning electron microscopy (FESEM) after fracturing in liquid nitrogen. Dried samples were coated with gold ions using an ion coater for $150 \mathrm{~s}$. The surface structure was visualized using FESEM (Hitachi S4160) at an accelerating voltage of $15 \mathrm{kV}$. Transmission electron microscopy (TEM) images were obtained using a LE0912-AB (LEO, Germany) transmission electron microscope with an accelerating voltage of $120 \mathrm{kV}$. Particles were deposited on carbon foil supported by a copper grid. Energy-dispersive X-ray analysis (EDX) was performed using an Oxford instruments EDX detector (UK) with an accelerating voltage of $10.0 \mathrm{kV}$. Milling was carried out in a planetary ball-mill using a hardened chromium steel vial (250 $\mathrm{mL}$ ) at room temperature in an argon atmosphere. The ball-to-powder mass ratio and the rotation speed of the vial were $10: 1$ and $350 \mathrm{r} / \mathrm{min}$, respectively.

\subsection{Catalyst preparation}

Empty chicken eggshells were collected from household waste and washed with warm tap-water. The adhering membranes were separated manually. The eggshells were then washed with distilled water and dried at $120{ }^{\circ} \mathrm{C}$ for $1 \mathrm{~h}$. The eggshells were milled in a planetary ball-mill for $2 \mathrm{~h}$, and the eggshell powder was calcined at $900{ }^{\circ} \mathrm{C}$ for $1 \mathrm{~h}$. The resulting material was denoted by nano-CaO.

\subsection{General procedure for synthesis of pyrano[4,3-b]pyrans}

A mixture of 4-chlorobenzaldehyde $(0.14 \mathrm{~g}, 1 \mathrm{mmol})$, malononitrile ( $0.07 \mathrm{~g}, 1 \mathrm{mmol})$, and 4-hydroxy-6-methyl-2H-pyran-2-one $(0.126 \mathrm{~g}, 1 \mathrm{mmol})$ was stirred thoroughly at $120{ }^{\circ} \mathrm{C}$ under solvent-free conditions in the presence of a catalyst amount of nano-CaO $(0.1 \mathrm{~g})$ to afford the corresponding pyrano[4,3-b]pyran in excellent yield. After completion of the reaction (thin-layer chromatography), hot EtOH was added and the reaction mixture was stirred for $5 \mathrm{~min}$. Then the solid catalyst was filtered from the soluble products and washed with hot EtOH. After cooling, the crude products were precipitated. Pure pyrano[4,3- $b]$ pyrans were obtained in high yields without further purification. All compounds were known in the literature [28,36-38] and the NMR and IR spectra of the products were in agreement with earlier data [28,36-38].

Spectra data of two selected compounds are as following.

2-amino-7-methyl-5-oxo-4-(4-chlorophenyl)-4H,5 H-pyrano [4,3-b]pyran-3-carbonitrile (Table 2, Entry 2): pale-yellow crystals, mp $227-229{ }^{\circ} \mathrm{C}$. IR (KBr, cm$\left.{ }^{-1}\right)$ : 3383, 3324, 3195, 2201, 1710, 1674, 1645, 1597, 1488, 1445, 1414, 1384, 1261, 1141, 1092, 1015, 981, 854, 830, 807, 777, 511. ${ }^{1} \mathrm{H}$ NMR (400.2 MHz, DMSO, $\delta$ ): 2.23 (s, 3H, CH 3$), 4.33(\mathrm{~s}, 1 \mathrm{H}, \mathrm{CH}), 6.29(\mathrm{~s}, 1 \mathrm{H}$, $=\mathrm{CH}), 7.23(\mathrm{~d}, 2 \mathrm{H}, J=8.4 \mathrm{~Hz}, \mathrm{ArH}), 7.26\left(\mathrm{~s}, 2 \mathrm{H}, \mathrm{NH}_{2}\right), 7.38(\mathrm{~d}, 2 \mathrm{H}$, $J=8.4 \mathrm{~Hz}, \mathrm{ArH}$ ). ${ }^{13} \mathrm{C}$ NMR (400.2 MHz, DMSO, $\delta$ ): 19.8, 36.2, 
57.9, 98.4, 100.7, 119.6, 128.8, 129.9, 132.1, 143.0, 158.5, 158.7, 161.8, 163.6.

2-amino-7-methyl-5-oxo-4-(3-nitrophenyl)-4H,5H-pyrano[4, 3-b]pyran-3-carbonitrile (Table 2, Entry 3): pale-yellow crystals, mp $230-232{ }^{\circ} \mathrm{C}$. IR $\left(\mathrm{KBr}, \mathrm{cm}^{-1}\right)$ : $3400,3327,2198,1716$, $1615,1526,1448,1385,1263,1200,1144,1024,978,817$, 759, 733. ${ }^{1} \mathrm{H}$ NMR (400.2 MHz, DMSO, d): $2.24\left(\mathrm{~s}, 3 \mathrm{H}, \mathrm{CH}_{3}\right), 4.53$ $(\mathrm{s}, 1 \mathrm{H}, \mathrm{CH}), 6.75(\mathrm{~s}, 1 \mathrm{H},=\mathrm{CH}), 7.35\left(\mathrm{~s}, 2 \mathrm{H}, \mathrm{NH}_{2}\right), 7.67(\mathrm{t}, J=8.0$ $\mathrm{Hz}, 1 \mathrm{H}, \mathrm{ArH}), 7.72(\mathrm{tt}, J=8.0 \mathrm{~Hz}, J=1.2 \mathrm{~Hz}, 1 \mathrm{H}, \mathrm{ArH}), 8.15(\mathrm{t}, J=$ $2.0 \mathrm{~Hz}, 1 \mathrm{H}, \mathrm{ArH}$ ), 8.17 (dd, dd, $J=8.0 \mathrm{~Hz}, J=2.0 \mathrm{~Hz}, J=1.2 \mathrm{~Hz}, 1 \mathrm{H}$, ArH). ${ }^{13 C}$ NMR (400.2 MHz, DMSO, $\delta$ ): 19.9, 36.4, 58.2, 98.3, 100.6, 119.7, 128.6, 129.8, 132.2, 143.1, 158.7, 159.0, 162.3, 163.7.

\section{Results and discussion}

The characterization results showed that the $\mathrm{CaO}$ was the most abundant component (98.6\%) in the nanocatalyst; this was associated with the presence of $\mathrm{CaCO}_{3}$. The nano-eggshell catalyst also contained small amounts of $\mathrm{Mg}(0.39 \%), \mathrm{P}$ (0.35\%), Sr (0.3\%), Si (0.3\%), K (0.014\%), Na (0.023\%), and Zn $(0.003 \%)$. Waste eggshell can therefore be considered chemically to be a relatively pure, natural carbonate-based material.

Figure 1(3) shows the IR spectra of commercially available $\mathrm{CaCO}_{3}$. The broad transmission band at approximately 3436 $\mathrm{cm}^{-1}$ can be attributed to $\mathrm{OH}$ stretching vibration from residual water. The weak band at $1632 \mathrm{~cm}^{-1}$ corresponds to $\mathrm{C}=0$ bonds from carbonate. Two well-defined IR bands at 1426, 873, and $700 \mathrm{~cm}^{-1}$ are attributed to asymmetric C-O stretching and out-of-plane and in-plane bending modes, respectively, for $\mathrm{CO}_{3}{ }^{2-}$ molecules.

Figure 1(2) shows the spectrum of calcined commercially available $\mathrm{CaCO}_{3}$. The presence of a peak at $3647 \mathrm{~cm}^{-1}$ is attributable to $\mathrm{OH}$ in $\mathrm{Ca}(\mathrm{OH})_{2}$ formed during adsorption of water by $\mathrm{CaO}$. The wide and strong band at around $500 \mathrm{~cm}^{-1}$ corresponds to the $\mathrm{Ca}-\mathrm{O}$ bond. The IR spectrum of the nano- $\mathrm{CaO}$ (Fig. 1(1)) had peaks at the same wavenumbers as that of calcined $\mathrm{CaCO}_{3}$, indicating that the nano-CaO based on eggshells and the calcined commercially available $\mathrm{CaCO}_{3}$ are chemically very similar. Our results regarding uncalcined and calcined

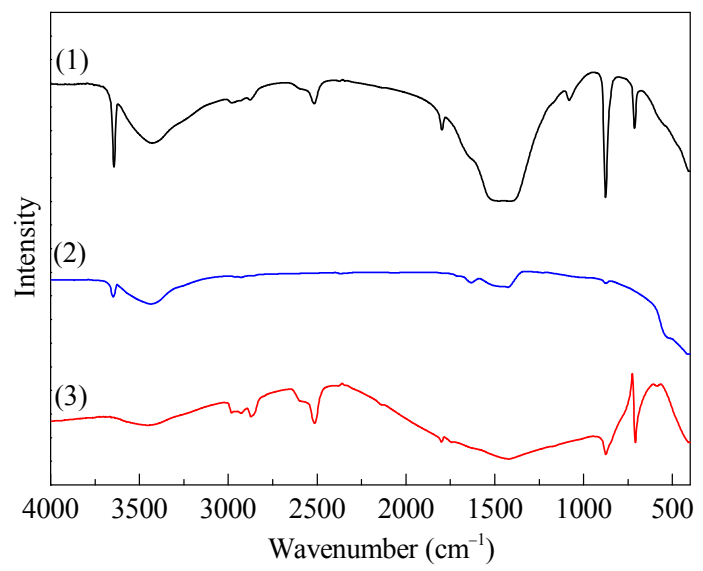

Fig. 1. FT-IR spectra of nano-CaO (1), calcined commercially available $\mathrm{CaCO}_{3}(2)$, and commercially available $\mathrm{CaCO}_{3}(3)$.

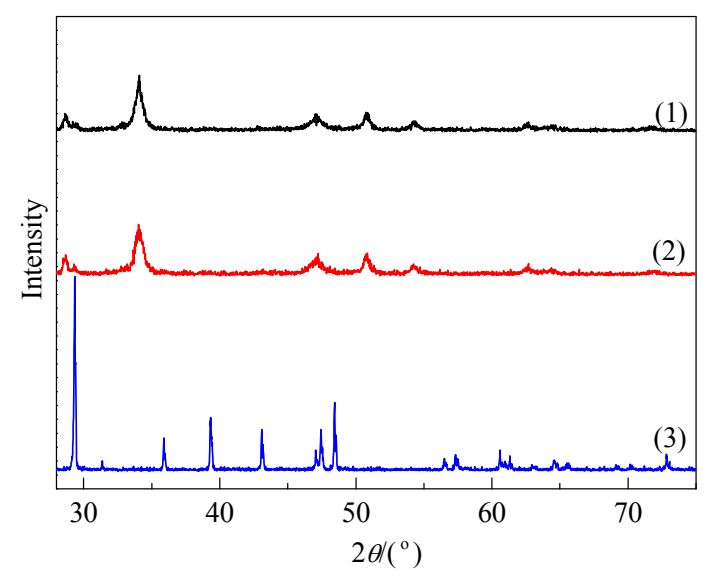

Fig. 2. XRD patterns of calcined commercially available $\mathrm{CaCO}_{3}$ (1), nano- $\mathrm{CaO}(2)$, and commercially available $\mathrm{CaCO}_{3}(3)$.

eggshells agree with those reported in the literature [5].

The XRD patterns of the raw eggshell powder and commercially available $\mathrm{CaCO}_{3}$ were identical, with peaks at $2 \theta=29.4^{\circ}$, indicating that calcite $\left(\mathrm{CaCO}_{3}\right)$ is the major phase in the waste eggshell (Fig. 2(3)). The XRD pattern of the nano-eggshell calcined at $900{ }^{\circ} \mathrm{C}$ for $1 \mathrm{~h}$ had a peak at $2 \theta=34.2^{\circ}$ (Fig. 2(2)). The major peak of the calcite phase $(2 \theta=29.4)$ was not observed in the XRD pattern of the nano-CaO, implying that the $\mathrm{CaCO}_{3}$ phase was completely transformed to the $\mathrm{CaO}$ phase (Fig. 2(2)). The XRD pattern of calcined commercially available $\mathrm{CaCO}_{3}$ (Fig. $2(1)$ ) had a peak at the same $2 \theta$ angle as that of the calcined eggshell.

The CaO crystallite size was calculated using the Scherrer equation. The calcined eggshell generated nanocrystalline $\mathrm{CaO}$ with a crystallite size of $40 \mathrm{~nm}$, whereas the calcined commercially available $\mathrm{CaCO}_{3}$ showed a very high degree of crystallinity with a crystallite size of more than $100 \mathrm{~nm}$.

A suitable eggshell calcination temperature was determined using TGA-DTA. As shown in Fig. 3, calcination below $600{ }^{\circ} \mathrm{C}$ did not lead to the formation of CaO. Complete conversion was obtained for calcination temperatures above $600{ }^{\circ} \mathrm{C}$, and nanocrystalline $\mathrm{CaO}$ was the major phase. The mass loss between 600 and $867{ }^{\circ} \mathrm{C}$ is $47.2 \%$ and is caused mainly by decomposition of calcite, with the formation of $\mathrm{CaO}$ and $\mathrm{CO}_{2}$.

Release of $\mathrm{CO}_{2}$ led to the creation of nanocrystalline $\mathrm{CaO}$.

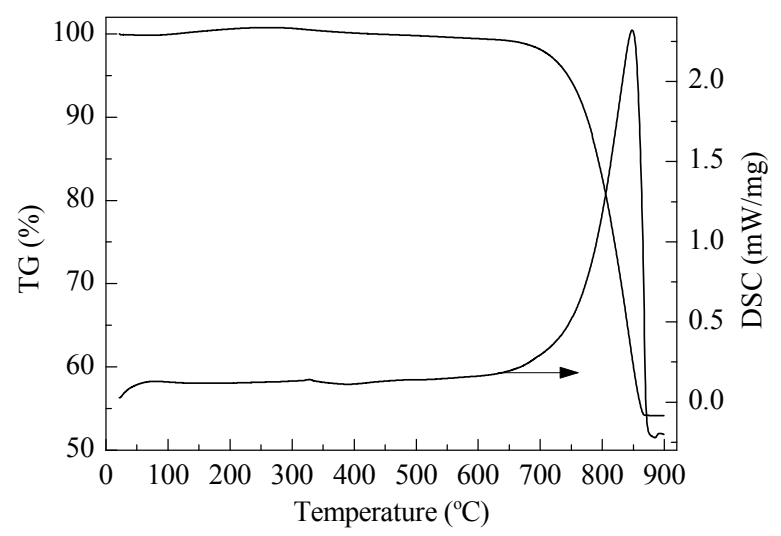

Fig. 3. TGA-DTA curves of nano-CaO based on eggshell. 

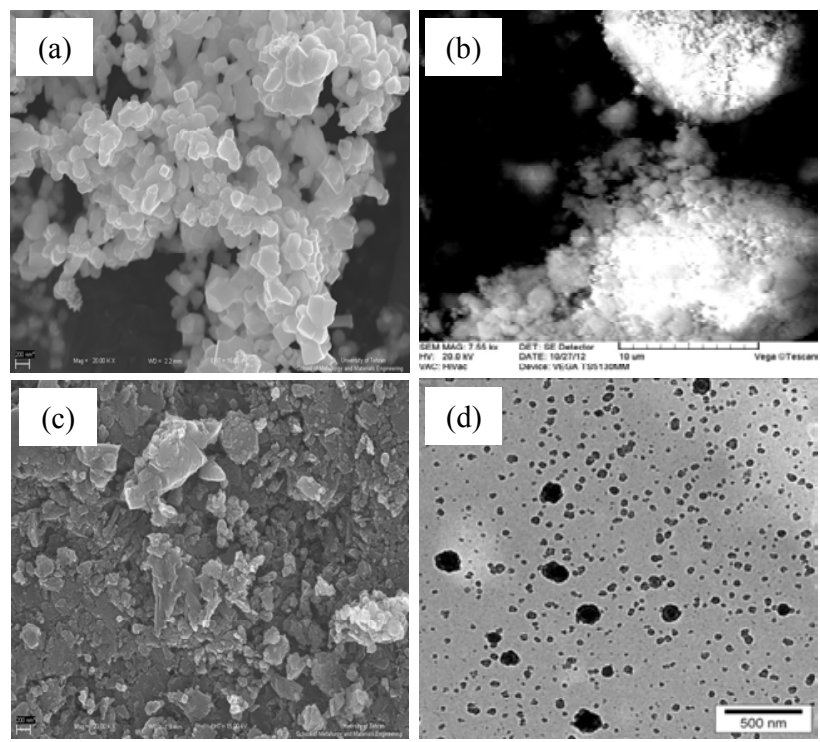

Fig. 4. FESEM images of nano-CaO (a), raw eggshell (b), calcined commercially available $\mathrm{CaCO}_{3}(\mathrm{c})$, and TEM image of nano-CaO (d).

The specimens also had high apparent porosities as a result of decomposition of $\mathrm{CaCO}_{3}$ with evolution of $\mathrm{CO}_{2}$ outside the eggshell powder structure. The effect of carbonate decomposition is clearly observed in the TEM and FESEM images of the sintered specimens, as shown in Fig. 4. The FESEM images of raw eggshell, nano-CaO obtained by thermal decomposition of eggshell, and calcined $\mathrm{CaCO}_{3}$ were compared. The images show that the porosity of the nano- $\mathrm{CaO}$ is higher than that of raw eggshell because of release of $\mathrm{CO}_{2}$ from inside the structure as a result of calcination. The mesoporous nature of the nanocatalyst, compared with the low porosity of the calcined $\mathrm{CaCO}_{3}$ surface, is responsible for the catalytic effect of the nano-eggshell. This effect is a result of the larger contact area resulting from the large number of pores and pits distributed over the entire eggshell surface.

Nitrogen physisorption analysis was performed to compare the surface areas of the nanocatalyst and calcined commercially available $\mathrm{CaCO}_{3}$. Brunauer-Emmett-Teller surface area analysis showed a high surface area of $8.0142 \mathrm{~m}^{2} / \mathrm{g}$, with an average particle size of $11 \mu \mathrm{m}$, for the nanocatalyst, whereas the values were $3.5421 \mathrm{~m}^{2} / \mathrm{g}$ and $23 \mu \mathrm{m}$ for eggshell that was only calcined. This is because ball-milling reduced the eggshell particle size. As shown in Table 1, the low surface area $\left(1.7364 \mathrm{~m}^{2} / \mathrm{g}\right)$ and larger particle size $(26 \mu \mathrm{m})$ of the calcined $\mathrm{CaCO}_{3}$ led to low porosity and low catalytic activity.

We then explored the catalytic activity of nano- $\mathrm{CaO}$ in the green synthesis of pyrano[4,3-b]pyran derivatives, using condensation reactions of various aromatic aldehydes $(1 \mathrm{mmol})$, 4-hydroxy-6-methyl-2H-pyran-2-one ( $1 \mathrm{mmol}$ ), and malononitrile $(1.2 \mathrm{mmol})$ under solvent-free conditions. Without the addition of a catalyst, no pyrano[4,3- $b]$ pyrans were formed, even after $10 \mathrm{~h}$, under the reaction conditions used.

To identify the optimum conditions, first, the effect of temperature on the reaction rate was studied for the preparation of pyrano[4,3-b]pyrans (Table 2). At $120{ }^{\circ} \mathrm{C}$, the reaction over nano-CaO proceeded to completion very rapid. Decreasing the
Table 1

Effect of average particle size of catalysts on the synthesis of 2-amino7-methyl-5-oxo-4-(4-chlorophenyl)-4H,5H-pyrano[4,3-b]pyran-3-carbo nitrile.

\begin{tabular}{lcccc}
\hline Catalyst & $\begin{array}{c}\text { Ball milling } \\
\text { Time }(\mathrm{h})\end{array}$ & $\begin{array}{c}\text { Average particle } \\
\text { size }^{\mathrm{a}}(\mu \mathrm{m})\end{array}$ & $\begin{array}{c}\text { Time } \\
(\mathrm{min})\end{array}$ & $\begin{array}{c}\text { Yield }^{\mathrm{b}} \\
(\%)\end{array}$ \\
\hline Nano-CaO & 2 & 11 & 45 & 96 \\
Calcined eggshell & 1 & 23 & 300 & 75 \\
Calcined eggshell & 0.5 & 47 & 300 & 20 \\
Calcined $\mathrm{CaCO}_{3}$ & 2 & 26 & 300 & 35 \\
\hline
\end{tabular}

a Determined by laser particle sizer.

bYield refers to isolated pure product.

\section{Table 2}

Nano-CaO-catalyzed synthesis of 2-amino-7-methyl-5-oxo-4-phenyl$4 H, 5 H$-pyrano[4,3-b] pyran-3-carbonitrile derivatives.

\begin{tabular}{lccc}
\hline Entry & $\mathrm{Ar}$ & Time (min) & Yield a $\left.^{\text {a }} \%\right)$ \\
\hline 1 & $\mathrm{C}_{6} \mathrm{H}_{5}$ & 5 & 94 \\
2 & $4-\mathrm{Cl}_{-} \mathrm{C}_{6} \mathrm{H}_{4}$ & 45 & 96 \\
3 & $3-\mathrm{NO}_{2}-\mathrm{C}_{6} \mathrm{H}_{4}$ & 35 & 93 \\
4 & $2,4-\mathrm{Cl}_{2}-\mathrm{C}_{6} \mathrm{H}_{4}$ & 25 & 95 \\
5 & $4-\mathrm{Br}_{-} \mathrm{C}_{6} \mathrm{H}_{4}$ & 25 & 94 \\
6 & $2-\mathrm{OH}-\mathrm{C}_{6} \mathrm{H}_{4}$ & 5 & 97 \\
7 & $4-\mathrm{OH}-\mathrm{C}_{6} \mathrm{H}_{4}$ & 20 & 98 \\
8 & $4-\mathrm{CH}_{3} \mathrm{O}-\mathrm{C}_{6} \mathrm{H}_{4}$ & 20 & 94 \\
9 & $4-\mathrm{CH}_{3}-\mathrm{C}_{6} \mathrm{H}_{4}$ & 30 & 93 \\
10 & $4-\left(\mathrm{CH}_{3}\right)_{2} \mathrm{~N}-\mathrm{C}_{6} \mathrm{H}_{4}$ & 15 & 96 \\
\hline
\end{tabular}

aYield refers to isolated pure product.

temperature led to decreased product yields and reaction rates. Next, the optimum amount of nanocatalyst in the range 0.02-0.2 g was evaluated. The highest yield was obtained with $0.1 \mathrm{~g}$ of catalyst. A further increase in the amount of catalyst up to $0.2 \mathrm{~g}$ did not have any significant effect on the product yield or reaction time.

To investigate the effect of particle size on the catalytic activity, calcined eggshells ball-milled for different time were used in the reaction. As shown in Table 1, the catalytic activity increased with decreasing particle size. The highest yield was obtained with nano-CaO of average particle size $11 \mu \mathrm{m}$. In addition, a comparison reaction was carried out to show that the nano- $\mathrm{CaO}$ was a better catalyst than commercially available $\mathrm{CaCO}_{3}$. As the data in Table 1 show, the reaction proceeded to completion in $45 \mathrm{~min}$, with a product yield of $96 \%$ over the nano- $\mathrm{CaO}$, whereas the corresponding values were $5 \mathrm{~h}$ and $35 \%$ over calcined $\mathrm{CaCO}_{3}$. Since the catalytic activity of the catalysts agreed well with the specific surface areas and catalyst particle size, it is logical to conclude that mesoporous $\mathrm{CaO}$ with crystals of reduced size is a more effective catalyst than calcined $\mathrm{CaCO}_{3}$ with a larger particle size and low porosity.

The generality of this reaction was examined using different aldehydes (Table 2). In all cases, the reactions gave the corresponding products in good to excellent yields (93\%-98\%) in very short reaction time (5-45 $\mathrm{min}$ ). This method offers significant improvements with regard to the scope of the transformation, simplicity, and green aspects, by avoiding expensive, hazardous, or corrosive catalysts.

A possible mechanism for the formation of the products is shown in Scheme 2. The reaction occurs via the initial for- 


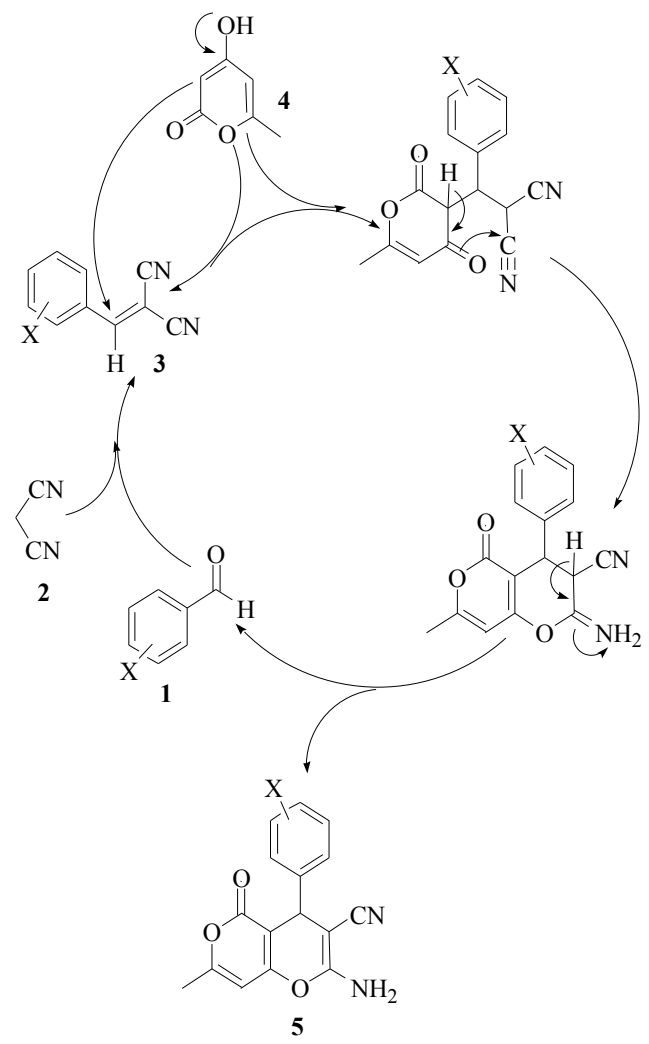

Scheme 2. Plausible mechanistic pathway for synthesis of pyrano[4,3-b]pyran derivatives.

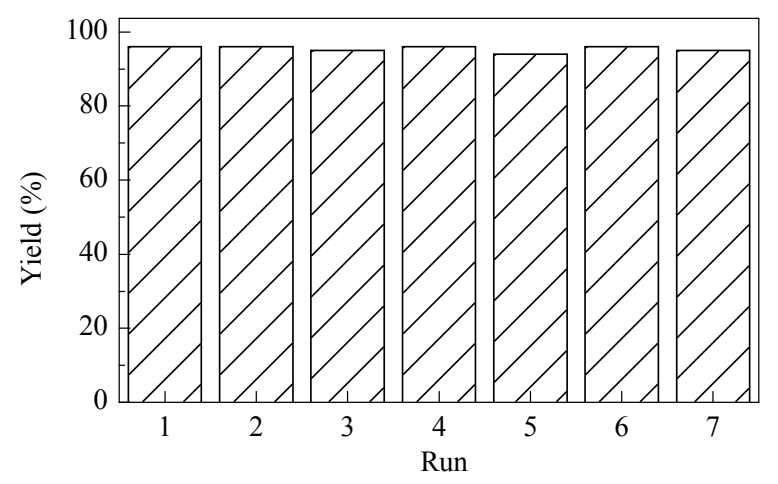

Fig. 5. Nano-CaO recycling experiments.

mation of benzilidenemalononitrile $\mathbf{3}$ by nucleophilic addition of malononitrile 2 to aromatic aldehyde $\mathbf{1}$, followed by dehydration. Subsequent Michael addition of 4-hydroxy-6-methyl- $2 H$-pyran-2-one 4 to 3 , followed by cyclization, affords the corresponding product $\mathbf{5}$.

The reusability of the catalyst in the synthesis of pyrano[4,3- $b]$ pyran derivatives was examined (Fig. 5). The catalyst was recovered after each run, washed three times with hot EtOH, dried in an oven at $120^{\circ} \mathrm{C}$, and tested for its activity in subsequent runs. We found that the catalyst could be reused seven times without loss of catalytic activity.

\section{Conclusions}

In summary, the easy and rapid ball-mill-assisted prepara- tion of nano-CaO based on eggshell waste was explored. Also, a green, rapid, and highly efficient protocol for the one-pot synthesis of pyrano[4,3- $b]$ pyrans under thermal solvent-free conditions, using an inexpensive and green catalyst, was developed. The nano-CaO was reused several times without any loss of catalytic activity and reusability. This green catalyst is a novel and biocompatible nanocatalyst based on eggshell waste; it can catalyze organic transformations and reduce environmental problems. This is the first use of eggshell waste material as a nano-sized natural $\mathrm{CaO}$ catalyst in organic synthesis.

\section{Acknowledgments}

The financial support of the Iran National Science Foundation (INSF) and support of the Graduate University of Advanced Technology are gratefully acknowledged (project 91004279).

\section{References}

[1] Chavan S S, Degani M S. Green Chem, 2012, 14: 296

[2] Kumar A, Gupta M K, Kumar M. Green Chem, 2012, 14: 290

[3] Zhang Q, Su H, Luo J, Wei Y Y. Green Chem, 2012, 14: 201

[4] Soleymani L, Fang Z C, Sargent E H, Kelley S O. Nature Nanotechnol, 2009, 4: 844

[5] Liao H H, Mutvei H, Sjöström M, Hammarström L, Li J G. Biomaterials, 2000, 21: 457

[6] Borrelli J Jr, Prickett W D, Ricci W M. Clin Orthop Relat Res, 2003, 411: 245

[7] Bhumiratana S, Grayson W L, Castaneda A, Rockwood D N, Gil E S, Kaplan D L, Vunjak-Novakovic G. Biomaterials, 2011, 32: 2812

[8] Siddharthan A, Kumar T S S, Seshadri S K. Biomed Mater, 2009, 4: 045010/1

[9] Gao Y, Xu C L. Catal Today, 2012, 190: 107

[10] Mosaddegh E, Hassankhani A. Catal Commun, 2013, 33: 70

[11] Devabhaktuni S, Prasad S. J Nanosci Nanotechnol, 2009, 9: 6299

[12] Dylewicz R, Khokhar A Z, Wasielewski R, Mazur P, Rahman F. Nanotechnol, 2011, 22: 055301

[13] Wan Y, Kim Y T, Li N, Cho S K, Bachoo R, Ellington A D, Iqbal S M. Cancer Res, 2010, 70: 9371

[14] Yang F, Murugan R, Ramakrishna S, Wang X, Ma Y X, Wang S. Biomaterials, 2004, 25: 1891

[15] Subramanian A, Krishnan U M, Sethuraman S. Biomed Mater, 2011, 6: $025004 / 1$

[16] Yoshii T, Dumas J E, Okawa A, Spengler D M, Guelcher S A. J Biomed Mater Res B, 2012, 100: 32

[17] Asghar W, Kim Y T, Ilyas A, Sankaran J, Wan Y, Iqbal S M. Nanotechnol, 2012, 23: 475601

[18] Siva R K D, Siddharthan A, Seshadri S K, Sampath K T S. J Mater Sci, Mater Med, 2007, 18: 1735

[19] Gergely G, Weber F, Lukacs I, Toth A L, Horvath Z E, Mihaly J, Balazsi C. Ceram Int, 2010, 36: 803

[20] Witoon T. Ceram Int, 2011, 37: 3291

[21] Uher M, Konecny V, Rajniakova O. Chem Pap, 1994, 48: 282

[22] Perez-Perez M J, Balzarini J, Rozenski J, De-Clercq E, Herdewijn P. Bioorg Med Chem Lett, 1995, 5: 1115

[23] Takao H, Murai K, Yasudomi N, Goto T, Umetsu N, Horie T.J Pestic Sci, 1994, 19: 131

[24] Khafagy M M, Abd El-Wahab A H F, Eid F A, El-Agrody A M. Farmaco, 2002, 57: 715

[25] Smith P W, Sollis S L, Howes P D, Cherry P C, Starkey I D, Cobley K 


\section{Graphical Abstract}

Chin. J. Catal., 2014, 35: 351-356 doi: 10.1016/S1872-2067(12)60755-4

Preparation and characterization of nano-CaO based on eggshell waste: Novel and green catalytic approach to highly efficient synthesis of pyrano[4,3-b]pyrans

Elaheh Mosaddegh*, Asadollah Hassankhani Graduate University of Advanced Technology, Iran

The ball-mill-assisted preparation by thermal decomposition of nano-CaO derived from chicken eggshell waste was reported as a novel, bioactive, and heterogeneous catalyst with high catalytic activity and reusability in the green synthesis of pyrano[4,3-b]pyrans.

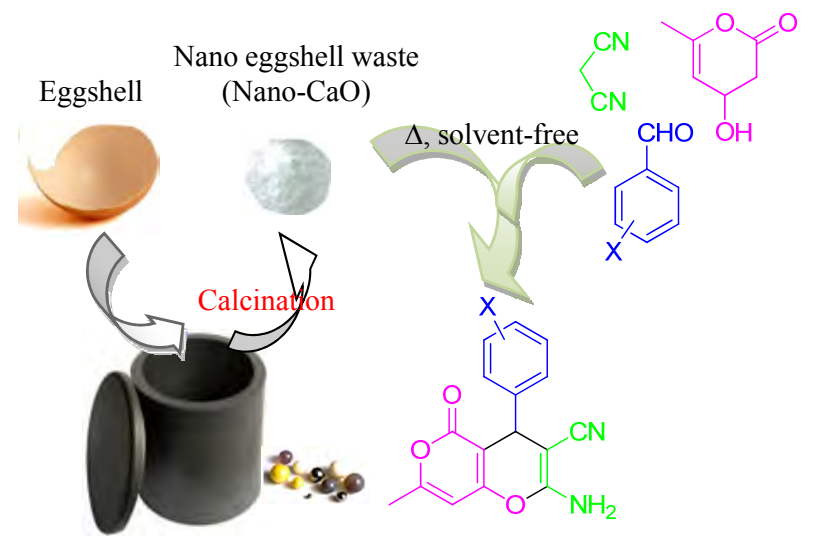

Bioorg Med Chem Lett, 2007, 17: 3065

[32] Kostova I. Mini-Rev Med Chem, 2006, 6: 365

[33] Nayyar A, Jain R. Curr Med Chem, 2005, 12: 1873

[34] Fylaktakidou K C, Hadjipavlou-Litina D J, Litinas K E, Nicolaides D N. Curr Pharm Des, 2004, 10: 3813

[35] Asres K, Seyoum A, Veeresham C, Bucar F, Gibbons S. Phytother Res, 2005, 19: 557

[36] Wang X S, Zhou J X, Zeng Z S, Li Y L, Shi D Q, Tu S J. Arkivoc, 2006, xi: 107

[37] Stoyanov E V, Ivanov I C, Heber D. Molecules, 2000, 5: 19

[38] Rajguru D, Keshwal B S, Jain S. Med Chem Res, 2013, 22: 5934

[39] Mosaddegh E, Hassankhani A. Tetrahedron Lett, 2011, 52: 488

[40] Mosaddegh E. Ultrasonics Sonochem, 2013, 2: 1436 